\title{
Females alter their song when challenged in a sex-role reversed bird species
}

\author{
Nicole Geberzahn • Wolfgang Goymann • \\ Christina Muck • Carel ten Cate
}

Received: 17 April 2009/Revised: 16 July 2009 /Accepted: 17 July 2009/Published online: 20 August 2009

(C) The Author(s) 2009. This article is published with open access at Springerlink.com

\begin{abstract}
Birdsong serves to attract mates and to deter territorial rivals. Even though song is not restricted to males, this dual function has almost exclusively been demonstrated for male song. To test the generality of hypotheses on birdsong, we investigated female song in the sex-role reversed, classically polyandrous African black coucal (Centropus grillii) in the context of female-female competition. We compared spontaneously vocalizing females with females vocally responding to a playback simulating a conspecific intruder. Females changed vocal parameters in response to playbacks: They lowered the pitch of their vocalizations and enhanced the duration of song elements when being challenged. Also, the composition of the vocalizations was altered. There was no significant correlation between pitch and body size parameters in spontaneous song, but there was for response songs, with larger females having a lower pitch. These changes in vocal properties suggest that the vocalizations are important for mutual assessment of competitive abilities in females. Our findings confirm the general role of intrasexual competition in vocal communication of birds.
\end{abstract}

Communicated by R. Gibson

Electronic supplementary material The online version of this article (doi:10.1007/s00265-009-0836-0) contains supplementary material, which is available to authorized users.

N. Geberzahn $\cdot$ C. ten Cate

Institute of Biology, Behavioural Biology, Leiden University,

P.O. Box 9505, 2300 RALeiden, The Netherlands

N. Geberzahn $(\triangle) \cdot$ W. Goymann $\cdot$ C. Muck

Department of Behavioural Neurobiology,

Max Planck Institute for Ornithology,

Eberhard-Gwinner-Str. 6a,

82319 Seewiesen, Germany

e-mail: geberzahn@orn.mpg.de
Keywords Female birdsong · Sex-role reversal .

Signal evolution · Aggressive signals · Signal reliability

Vocal communication $\cdot$ Centropus grillii

In most temperate-zone bird species, only males sing and their song serves to attract mates and to deter territorial rivals (Catchpole and Slater 2008). The song of passerine birds provides the best-studied case, but vocalizations of many non-passerine species serve the same functions and hence can be considered as song as well (cf. Searcy and Nowicki 2005). Traditionally, the dual function of song is thought to be related to "typical" sex roles: females, which make a larger parental investment, are generally the limiting sex and thus expected to be choosy. In contrast, males are more competitive and most have evolved elaborate secondary sexual signals, including song (Andersson 1994). In birds, females often choose males according to variation in the males' song, while sexual selection also affects signal parameters through competition between rival males (Berglund et al. 1996). However, this "traditional" view fails to explain the existence of secondary sexual traits in females (Clutton-Brock 2007), and the evolution of sex roles and secondary sexual signals might be more complex than initially suggested (Kokko and Jennions 2008). For example, in passerines, song in both sexes might be the ancestral trait, and male-biased song production might be the result not of sexual selection for song in males but of selection against song in females (Price et al. 2009). Accordingly, where females sing, there might have been no such selection against female song: For example, in some species, circumstances with increased female-female competition do occur (such as scarcity of breeding opportunities or facultative polygyny), and in such circumstances, females sometimes sing as well (Langmore 1998, 2000). Likewise, singing females are rather common 
among tropical birds, which often exhibit sex role convergence (reviews in Stutchbury and Morton 2001; Slater and Mann 2004) and given that the majority of bird species breed in the tropics it is debatable whether "typical" sex roles are really so typical. It is increasingly recognized that female song - if it occurs - might serve similar functions to those of male song (Langmore 2000; Riebel 2003; Riebel et al. 2005; Garamszegi et al. 2007). Even though there have been some studies on female song (e.g., Cooney and Cockburn 1995; Brunton and Li 2006; Price et al. 2008; Illes and Yunes-Jimenez 2009), it is still a highly neglected issue in birdsong research.

From studies on males' singing behavior, it is known that, during a territorial conflict, birds vocally communicate their competitive potential, and this helps them to resolve a conflict without necessarily engaging in costly physical fights (reviewed in Todt and Naguib 2000; ten Cate et al. 2002). In this context, signals can only evolve if they are honest, as otherwise receivers would refrain from responding to the signals. A fundamental question is how such signal honesty is maintained (Gil and Gahr 2002). A bird's fighting ability is determined, among other factors, by its physical quality. Several studies have investigated how between-individual variation in vocal parameters such as structural features of the song (i.e., spectro-temporal properties) might be related to fighting ability. In many, but not all, of those studies, factors such as body size or condition to which the song features are physically linked seem to guarantee the honesty of signals (reviewed in ten Cate et al. 2002). For example, heavier collared doves (Streptopelia decaocto) produce more extended vocalizations (Ballintijn and ten Cate 1999) as well as modulated elements that are probably more difficult to produce (ten Cate et al. 2002). In other species (e.g., in barn swallows, Hirundo rustica, Galeotti et al. 1997), low frequencies are only produced by large birds.

An individual's current aggressive intent can also crucially influence the outcome of a conflict and might be indicated by intra-individual variation in song. For males such variation reflecting motivational state has, for example, been described as temporal or pattern-specific adjustment to an opponent's singing (review in Todt and Naguib 2000 ) or the use of specific categories of songs in specific contexts (e.g., Järvi et al. 1980; Catchpole 1983; Nelson and Croner 1991; Staicer 1996; Trillo and Vehrencamp 2005). Other studies have investigated how the variation of song features might give varied information about aggressive motivation (e.g., Hill and Lein 1987; Galeotti et al. 1997; Illes et al. 2006; Price et al. 2006). For example black-capped chickadees (Poecile atricapillus) shift the frequency of their song in agonistic interactions, and it has been suggested that such frequency-shifted songs communicate a higher level of aggressive motivation than non- shifted songs (Hill and Lein 1987; Otter et al. 2002; Mennill and Ratcliffe 2004).

In some exceptional bird species, sex roles are reversed. In these cases, females compete more intensely than males for access to mates or resources (reviewed, e.g., in Ligon 1999; Eens and Pinxten 2000; Andersson 2005). According to the principles of sexual selection, females rather than males should evolve secondary sexual signals in such species (Clutton-Brock 2007). In sex role-reversed pipefish, for example, females use temporary color ornaments in female-female interactions (reviewed in Berglund and Rosenqvist 2003). To the best of our knowledge, there is only one study so far on song properties of females in a partially sex-role reversed bird species (pheasant coucal Centropus phasaninus, Maurer et al. 2008), although there are additional reports of higher song rates in females than in males in one classically polyandrous species (African black coucal, Centropus grillii, Goymann et al. 2004) and one partially sex-role reversed species (greater vasa parrot, Caracopsis vasa, Ekstrom et al. 2007). Likewise, sex-role reversal in song has been suggested for streak-backed orioles (Icterus pustulatus, Price et al. 2008) and for stripeheaded sparrows (Aimophila ruficauda ruficauda, Illes and Yunes-Jimenez 2009). Thus, it is little understood whether and how vocal signals in species with various degrees of sex-role reversal are affected by sexual selection. To fill this gap, we studied vocalizations in the context of femalefemale competition in African black coucals. They have a classically polyandrous mating system (i.e., females mate simultaneously with up to four males, whereas males form bonds with only one female during a given breeding season); females are larger than males, aggressively defend large territories that contain smaller and non-overlapping subterritories of their males and use vocalizations to defend these territories. In contrast, males rarely vocalize, and each male builds his own nest and incubates and cares for his social offspring in general without any help from the female (Vernon 1971; Goymann et al. 2004, 2005). Furthermore, the sexes are size dimorphic, with females being $69 \%$ heavier than males (Goymann et al. 2004). Therefore, black coucals make an excellent model with which to study vocal communication in a species with reversed sex roles. Studies on female song are timely as they provide the possibility for a critical test of the generality of sexual selection theories on signal evolution. If these theories hold, female song should follow similar patterns in the context of femalefemale competition as can be found for male song in the context of male-male competition.

The current study examines intra- and inter-individual vocal variation in the song of female African black coucals. We studied intra-individual variation in the signal to see whether the parameters of song changed when females were challenged by a playback of conspecific song 
simulating a territorial intrusion in comparison to when they were singing spontaneously. Our prediction was that, if females use song properties to communicate their aggressive intent, i.e., their current motivational state, then they should modify vocal parameters in a context-specific manner. Furthermore, we hypothesized that inter-individual variation in acoustic properties might provide honest signals of a female's fighting ability. If so, we predicted that vocal parameters would correlate with morphometric measures.

\section{Methods}

Study site, subjects, and their vocalizations

We studied African black coucals (Family: Cuculidae) in the Usangu wetland $\left(8^{\circ} 41^{\prime} \mathrm{S}, 34^{\circ} 5^{\prime} \mathrm{E}\right)$ in southwestern Tanzania. African black coucals are considered to be shortdistance migrants and establish breeding territories during the rainy season from approximately January to June. While part of the birds remain in the breeding area, the majority of birds may seek suitable habitat elsewhere during the non-breeding season (W. Goymann, personal observation). As the habitat suitable for breeding changes on a year-to-year basis, individual birds are not site faithful. The study was conducted during the breeding seasons in 2005 (2 February to 17 May) and 2006 (7 March to 16 May). In total, we studied 42 birds (20 in 2005 and 22 in 2006) of which 30 were caught using mist nets and color and/or metal ringed (20 in 2005 and 10 in 2006). For all subjects caught, we took the following morphometric measurements: body mass (to the nearest $1 \mathrm{~g}$ ), right tarsus length as a measure of the skeletal body size (to the nearest $0.1 \mathrm{~mm}$ ), and bill length (to the nearest $1 \mathrm{~mm}$ ). In addition, 24 of the birds (18 in 2005 and six in 2006) were equipped with a Holohil BD-2G radio transmitter $(<2 \mathrm{~g}$; Holohil Systems Ltd, Carp, Ontario, Canada) using a Rappole harness (Rappole and Tipton 1991) made out of soft polyethylene microtubing (0.9-mm diameter). Females weigh on average $165.5 \mathrm{~g}$ (Goymann et al. 2004); thus, the weight of the radio transmitter is less than $1.2 \%$ of their body mass. In fact, earlier studies showed that females carrying radio transmitters readily reproduced (Goymann et al. 2004, 2005). Thus, it seems very unlikely that carrying a radio transmitter affects a female's singing behavior. Further details are published in Goymann and Wingfield (2004), and Goymann et al. (2004, 2005).

African black coucals have five different types of vocalizations (Goymann et al. 2004). Those ones that serve the same functions as the song of passerine birds were labeled as song here. The song of African black coucals typically consists of two parts, the whoot part and the k'tuc part (Fig. 1a, d and Goymann et al. 2004; terms are onomatopoetic); however, it can also be composed of either part without the other. The first part consists of low-pitched elements, the whoots, and the second part consists of syllables, the k'tuc syllables. K'tuc syllables typically contain two elements, but some subjects sometimes produce syllables with one or three elements.

\section{Recording methods for spontaneous singing}

Recordings were made using a Sennheiser ME66/K6 microphone connected to a Marantz PMD 670 solid-state recorder (sample rate: 2005, $44.1 \mathrm{kHz} ; 2006,22.05 \mathrm{kHz}$,
Fig. 1 a Spectrogram of a song of a spontaneously singing female, $\mathbf{b}$ power spectrum of a 0.5 -ms time steps in a whoot element (indicated by $i$ in $\mathbf{a}$ ), c power spectrum of a $0.5-\mathrm{ms}$ time steps in a k'tuc element (indicated by $i i$ in a). Peak frequencies $(\mathrm{PF})$ are indicated in the power spectra. d Spectrogram of a song of a reactively singing female. e Spectrogram of the "coo"
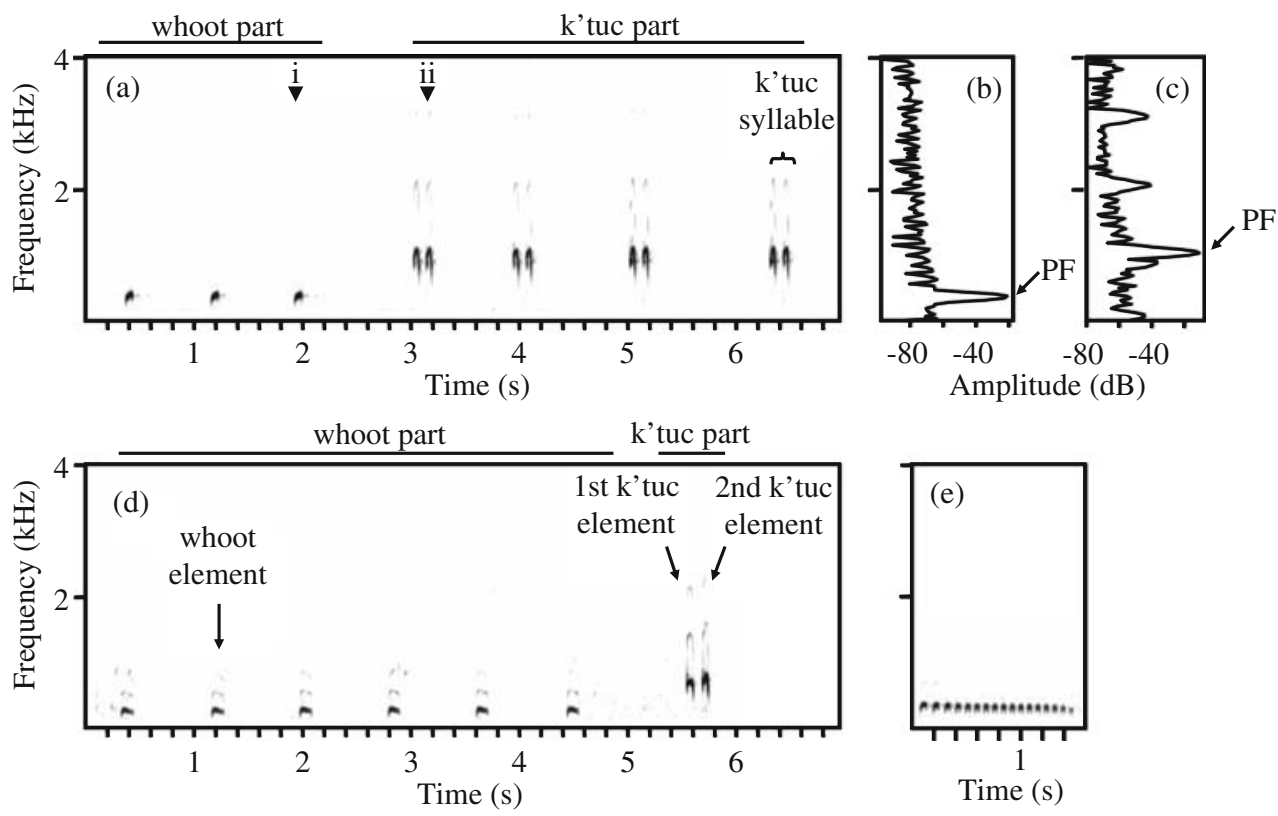
proven to be sufficient after the inspection of songs from 2005). We recorded songs between 0600 and 1200 hours and between 1700 and 1900 hours. Recordings of spontaneous singing were made of 20 subjects in 2005 (for which we obtained only these recordings) and of seven subjects in 2006 (for which we also obtained recordings of singing during playback, see below). We recorded spontaneously singing females on up to five different days (mean $\pm \mathrm{SD}=3 \pm 1.33$ days). During the recording sessions, we identified the ringed subjects or those equipped with a radio transmitter using either their rings and/or telemetry. Two subjects without rings and sender were recorded before the start of the playback experiments and were visually kept track of until the end of the experiment. We followed subjects as closely as possible and quietly narrated observed behavior into the silent pauses between their vocalizations. In particular, we checked whether a female was interacting with a conspecific or responding to a predator. Spontaneous singing was defined as singing without any indication of such interactions.

Playback experiments and recording methods during playback

We conducted two series of playback experiments on a total of 22 subjects in 2006, seven of which had also been recorded singing spontaneously. As stimuli, we used songs of 17 different spontaneously singing females that were recorded in 2005. There are many potential breeding habitats for black coucals in the Usangu plains, but habitat suitable for breeding in 1 year may not be suitable in the following year. Hence, ringed birds in our study population usually do not return to the study area in subsequent breeding seasons (recapture rate $<1 \%$, W. Goymann, unpublished data). It is thus very unlikely that the stimuli used for the playbacks were from birds known to the subjects (although we cannot rule out that they might have encountered those subjects on their non-breeding grounds). Stimuli for a given playback contained recordings of one female that were processed using Avisoft SASLAB Pro (R. Specht, Berlin, Germany) and CoolEdit96. The same stimuli were not broadcast to more than two subjects. These playbacks were designed to study the signal value of acoustic parameters as part of another study (Geberzahn et al., in preparation). In short, in one set of playback series, one test stimulus contained only whoot elements, while the other contained only k'tuc syllables (such element compositions of songs are within the species natural range). In the other set of playback series, one test stimulus contained song elements as recorded from a spontaneously singing female and the other contained the same elements, but whoot elements were lowered in frequency and increased in duration and k'tuc syllables were lowered in frequency (within the species natural range).

To broadcast the songs, we used a Blaupunkt $100 \mathrm{~W} \mathrm{CB}$ 4500 loudspeaker with a custom built-in Kemo MO34 amplifier connected to a Marantz PMD 670 solid-state recorder. Songs were broadcast at amplitude of ca. $85 \mathrm{~dB}$ at $1 \mathrm{~m}$ (CEL-231 sound level meter). The playback equipment was placed in the center of a subject's territory. Each experiment followed the same scheme and lasted for $44 \mathrm{~min}$ in total: $5 \mathrm{~min}$ pre-playback period of silence and three subsequent periods each lasting $13 \mathrm{~min}$ consisting of 3-min playback followed by $10 \mathrm{~min}$ of silence each. During the first playback period, we broadcast a lure playback to lure the female into the playback area. This lure playback was a song sequence as recorded from the same stimulus bird as the test stimuli when she was singing spontaneously (containing whoots and k'tucs). During the second and third playback periods, we broadcast the two test stimuli, with half of the subjects receiving one type of test stimulus first and the other half of the subjects receiving the other type of test stimulus first.

Observations of behavior were made by two observers, one being positioned on the top of a ladder for better vision from a distance of approximately $50-60 \mathrm{~m}$, and subjects were kept track of during the whole course of the experiment. Continuous stereo recordings were made using two Sennheiser ME66/K6 microphones (mounted close to the loudspeaker and pointing in opposite directions, two microphones to increase the likelihood of getting high quality recordings, as one was usually closer to the subject and had a better signal/noise ratio) connected to a Marantz PMD 670 solid-state recorder (sample rate, $22.05 \mathrm{kHz}$ ). As reactive singing, we define the singing of a territorial female during the $3 \mathrm{~min}$ of a test playback period or the $10 \mathrm{~min}$ thereafter (ignoring the lure period). During the territorial reaction of a female, a male was often around and sometimes followed her but did never take an active role, e.g., overall males produced less than $4 \%$ of all songs uttered during these 13-min periods. Thus, it was always the female that took the active role in territorial defense (cf. Goymann et al. 2004). All experiments were approved by the Tanzania Commission of Science and Technology and the Tanzania Wildlife Research Institute and comply with the current laws of Tanzania.

\section{Analysis of vocalizations}

As a measure of the composition of songs, we assessed the percentage of whoot elements in the total number of units within a song (counting as units either whoot elements or k'tuc syllables, e.g., the songs in Fig. 1 contain (a) $43 \%$ and (d) $86 \%$ of whoots). 
For the analysis of spectro-temporal parameters, we considered the following types of element: (1) whoot, (2) first k'tuc element, and (3) second k'tuc element (Fig. 1d, single k'tuc elements and the third element in k'tuc syllables containing three elements were not considered). We measured the duration and the mean peak frequency (MPF) of elements using sound analysis software developed by R. Lachlan ("Luscinia," R. Lachlan, Leiden University, The Netherlands, http://luscinia.sourceforge.net). Spectrograms were calculated by short-time Fourier transformation (frame duration, $12 \mathrm{~ms}$; Hamming window, time step, $0.5 \mathrm{~ms}$; frequency step, $10 \mathrm{~Hz}$; high pass filter, $50 \mathrm{~Hz}$ ). We based all measurements on fundamental frequency and calculated element duration (measured as the time elapsing between the onset and offset of the element) and one measure for element frequency, the MPF, as we had a strong a priori expectation for context-specific changes to occur in these parameters (changes are easily audible to the human ear and visible in spectrograms cf. Fig. 1). From different possible frequency parameters, we choose MPF, as it is least prone to variation in the signal/noise ratio. For each single element, MPF was calculated as the mean of the peak frequencies (PF) of all time steps (where PF is the frequency at the highest amplitude in the power spectrum, Fig. 1). For each song, the mean duration and MPF were calculated as the mean of the durations and MPFs of all elements of a given type in that song (thus, potential differences in the serial position of the element were leveled out). In total, we measured 44.6 \pm 21.3 (mean $\pm \mathrm{SD}$ ) songs per subject.

To rule out the possibility that the manipulations conducted on some of the playback stimuli might have led to non-typical responses, we compared seven vocal parameters (proportion of whoots, MPF, and duration of whoot, first and second k'tuc element) in the subject's vocalizations in response to the different types of stimuli. We found that different types of test playback stimuli had no effect on the seven vocal parameters when comparing mean values of reactive songs (13 paired sample $t$ tests and one Wilcoxon matched-pairs signed-ranks test for comparison within playbacks, seven independent samples $t$ tests for comparisons between playbacks, all $p \geq 0.1$ ). Thus, it is very unlikely that we elicited non-typical responses of our subjects when we presented them with manipulated stimuli.

Furthermore, we tested whether the seven vocal parameters changed over the course of the breeding season both in reactive and spontaneous singing. This was necessary as we needed to take such seasonal variation into account for further analysis. To this end, we calculated mean values of relevant parameters per day and subject and related them to the days the relevant songs were recorded.

We found seasonal effects on some parameters: The proportion of whoots decreased over the course of the breeding season in reactive singing (general linear model, $\left.F_{1,20}=6.25, R^{2}=0.24, t=-2.5, p=0.02\right)$. Spontaneously singing females sang their song elements with lower MPF early in the breeding season than they did later on (linear mixed models: whoot, $F_{1,20}=5.67, t=2.38, p=0.03$; first k'tuc, $F_{1,22}=3.52, t=1.88, p=0.07$; second k'tuc, $F_{1,22}=$ 6.76, $t=2.6, p=0.02)$. The duration of whoot elements decreased over the course of the breeding season during reactive singing (Spearman's rank correlation $n=22, r=-0.47$, $p=0.03)$. First k'tucs got shorter in duration in reactive singing (general linear model: first k'tuc, $F_{1,18}=5.15, R^{2}=$ $0.22, t=-2.27, p=0.04)$. All other parameters did not change over the course of the season: all $p \geq 0.13$.

To avoid such seasonal effects confounding the comparison between reactive and spontaneous singing, we excluded those recordings of spontaneous singing from further analysis that were made on days after reactive singing was recorded (except for the whoot elements of one subject that were still considered, as no earlier recordings of whoots in spontaneous singing were available; exclusion of this subject would not have altered the results). Changes in reactive singing over the course of the breeding season were all in the opposite direction to changes that occurred in response to the challenge. Therefore, we could keep all recordings of reactive singing in the analysis: if anything a seasonal effect would weaken the context-specific effect, thus rendering our analysis conservative.

From observations, it was obvious that contextspecific changes on spectro-temporal features were most pronounced in the initial vocal response. Later on, females seemed to return to their default (spontaneous) singing style. This is reflected in plotting frequency against duration for all reactive vocal elements: In most reactively singing females, duration and pitch of some elements clearly departed from the ranges shown by parameters during spontaneous singing (Fig. 2, top panel). However, the same subjects also produced elements within the range of spontaneous singing, resulting in a bimodal distribution during reactive singing (Fig. 2, top panel). In other subjects, these parameters showed a rather unimodal distribution (Fig. 2, bottom panel). To confirm such a transient effect, we compared the first songs that a female sang after being challenged by the test playbacks with the first songs she sang after a further 175 s (i.e., resulting in a time window of 175-228 s). For this comparison, we averaged values for all the subject's responses to test playbacks.

For a subset of females, we compared morphometric measurements with the MPF of the song element types in the different contexts.

In addition to the song measures taken, we counted the occurrence of another type of vocalization, the coo 
Fig. 2 Mean peak frequency $(M P F)$ and duration of song elements that two sample females (top and bottom panel) produced in reactive (crosses) and spontaneous (rectangles) singing. For reactive singing, single song elements are represented by symbols. For spontaneous singing, the rectangle represents the range of single song elements (with one demarcating line extended to improve visibility; for spontaneous singing, each single song element is not presented). A visual inspection of relevant distributions for all reactively singing subjects $(n=22)$ revealed a pattern resembling the top panel in 14 and the bottom panel in eight subjects

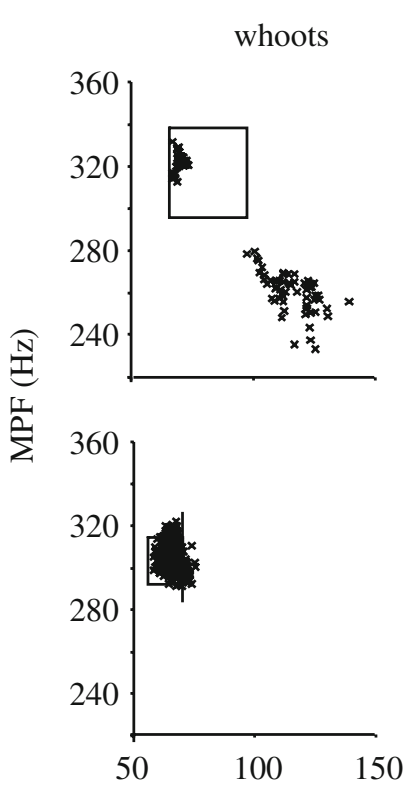

first k'tuc elements
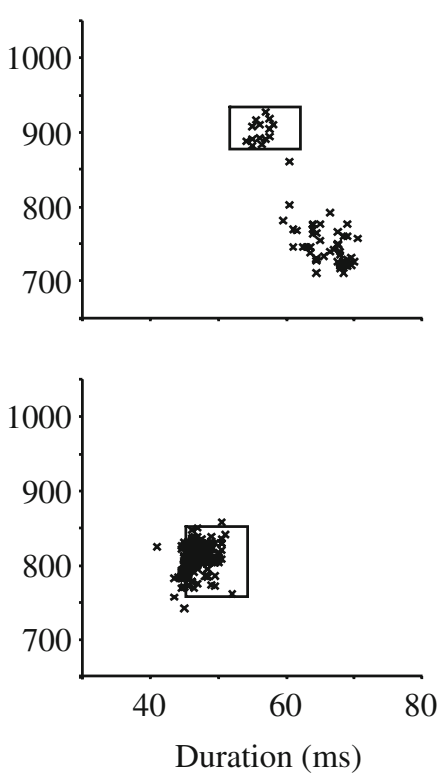

second k'tuc elements
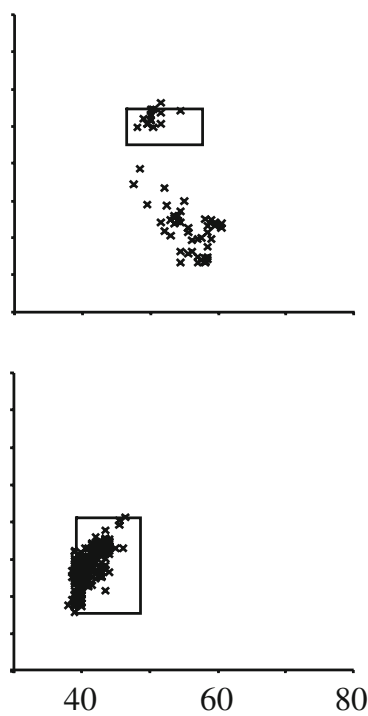

(Fig. 1e), in both spontaneous and reactive situations. The coo is a low-frequency sound, which is similar to the cooing of pigeons and has been invariably observed in close range agonistic situations by Goymann et al. (2004).

\section{Statistical analysis}

Statistical analyses were conducted using SPSS 15.0 and SYSTAT 12.0. We tested for normality using Shapiro-Wilk tests. In cases of normal distributions (either of the original or the log transformed data), we used a paired sample $t$ test or an independent sample $t$ test for paired and independent data, respectively. Where distributions were not normally distributed (even after log transformation), we used Wilcoxon matched-pairs signed-ranks tests for paired comparisons and Mann-Whitney $U$ tests for unpaired comparisons.

To test whether vocal parameters changed over the course of the breeding season, we used general linear models or linear mixed models implemented in SYSTAT (controlling for random intercepts and slopes, see Schielzeth and Forstmeier 2009) with day of recording as fixed effect and year and subject as random effects (except for parameters where residuals were not normally distributed even after log, square root, or Box-Cox transformations: here, we used Spearman's rank correlations).

To check for relationships between morphometric and acoustic parameters, we used Pearson's correlations tests. All tests were two-tailed, and we calculated exact $p$ values when samples were too small for asymptotic variants of nonparametric tests (Siegel and Castellan 1988; Bortz et al. 1990; Mundry and Fischer 1998).

\section{Results}

Context-specific variation in the composition of songs

The composition of songs varied with the context. In spontaneous singing, females sang more k'tucs than whoots: the mean proportion of whoots per subject ranged from $0 \%$ to $48.5 \%$ (mean $\pm \mathrm{SD}=19.4 \pm 12.3 \%$ ) when looking at all spontaneous singing subjects $(n=27)$. In contrast, the majority of our reactively singing females $(n=$ 22) sang more whoots than k'tucs: The mean proportion of whoots per subject ranged from $14 \%$ to $100 \%$ (mean $\pm \mathrm{SD}=$ $65.2 \pm 22.4 \%$ ). All subjects for which we had recordings from both contexts produced a higher proportion of whoots in their reactive than in their spontaneous singing (paired $t$ test, $t=5.04 ; d f=6 ; p=0.002$; Fig. 3 , effect sizes and their $95 \%$ confidence intervals for all results are given in the Electronic supplementary material). Comparing the additional females for which we had only recordings from either context also revealed that reactively singing females sang a higher proportion of whoots than spontaneously singing females (Mann-Whitney $U$ test, $U=10, n_{1}=15, n_{2}=20$, $p<0.001)$.

For the above analysis, we took into account all reactive songs (produced in the 3-min playback followed by $10 \mathrm{~min}$ of silence), as we could not find a temporal change in the composition of songs: The proportion of whoots did not differ in the first song females uttered after being challenged and a song $175 \mathrm{~s}$ after that first song (Wilcoxon matched-pairs signed-ranks test, $T=45$; $n=20 ; p=0.42)$. 


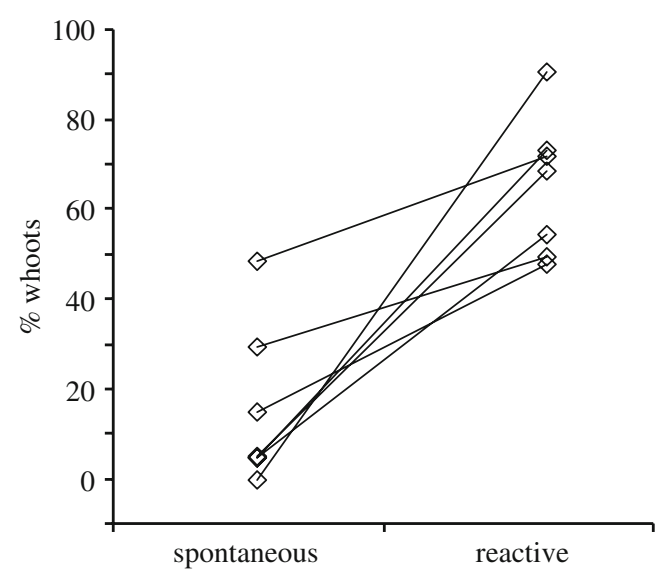

Fig. 3 Proportion of whoots in the songs of females singing spontaneously and reactively. Symbols represent mean values per subject of all songs (for reactive singing, grand mean of mean values obtained from different playbacks)

Transient effects of playbacks on spectro-temporal properties

To verify our observations that context-specific changes in spectro-temporal features were most pronounced in the initial vocal response, we first looked at transient effects of the playbacks. Whoot elements were both significantly lower pitched and significantly longer in duration in the first song after being challenged than later (Wilcoxon matched-pairs signed-ranks test: MPF, $T=173 ; n=19 ; p=$ 0.0008; duration, $T=29 ; n=19 ; p=0.006$ ). K'tuc elements were also significantly lower pitched in the first song than later, but their duration was not significantly different (paired $t$ test: first k'tuc elements, MPF, $t=3.6, d f=16, p=$ 0.002 ; duration, $t=-1.3, d f=16, p=0.2$; second k'tuc elements, MPF, $t=3.6, d f=16, p=0.002$; duration, $t=$ $-0.04, d f=16, p=0.97$; note that sample size varies as

Fig. 4 Mean peak frequency (MPF) and duration of the different element types in spontaneous and reactive singing. Symbols represent grand means (mean value per subject of mean value per song, for reactive singing: mean of the first song produced after different playbacks) some females did not sing the relevant elements any more after $175 \mathrm{~s}$ ).

Such a temporal change did not occur in spontaneous singing: We could not find a significant difference in MPF and duration between the first song in a bout of spontaneous singing and a song $175 \mathrm{~s}$ later (paired $t$ test: whoots, MPF, $t=1, d f=14, p=0.33$; duration, $t=1, d f=14, p=0.34$; first k'tuc elements, MPF, $t=0.6, d f=23, p=0.56$; duration, $t=-0.2 ; d f=23, p=0.87$; second k'tuc elements, MPF, $t=1$, $d f=23, p=0.32$; duration, $t=-0.3 ; d f=23, p=0.75$ ).

Due to the transient effect of the playback on spectrotemporal parameters, when comparing reactive singing to spontaneous singing in the following section, we therefore consider only the first song a subject produced after the start of the playback that contained the relevant song element (averaging values for all test playbacks that a subject was responding to).

Context-specific variation in spectro-temporal properties of song elements

Song elements in the first response song after playback were (or tended to be) lower pitched and longer in duration than in spontaneous singing with one exception: The duration of the second k'tuc element did not differ significantly between the contexts (Fig. 4, paired $t$ test: MPF, whoots, $t=-2.80, p=0.03$; first k'tuc elements, $t=$ $-3.88, p=0.008$; second k'tuc elements, $t=-4.24, p=0.005$; duration, whoots, $t=2.31, p=0.06$; first k'tuc elements, $t=$ 2.19, $p=0.07$; second k'tuc elements, $t=0.35, p=0.74$; all tests, $d f=6, n=7$ subjects recorded in both contexts). Comparing the additional females for which we had only recordings from either context confirmed these findings (independent sample $t$ tests: MPF, whoots, $t=-4.77, p=$ 0.0001 ; first k'tuc elements, $t=-4.47, p=0.0001$; second
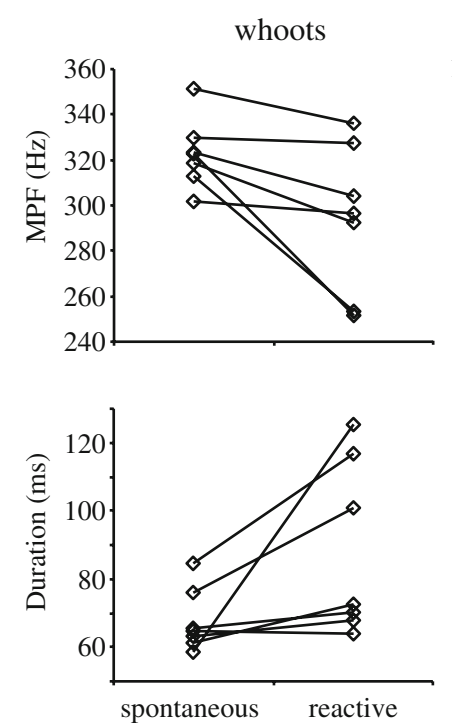

first k'tuc elements
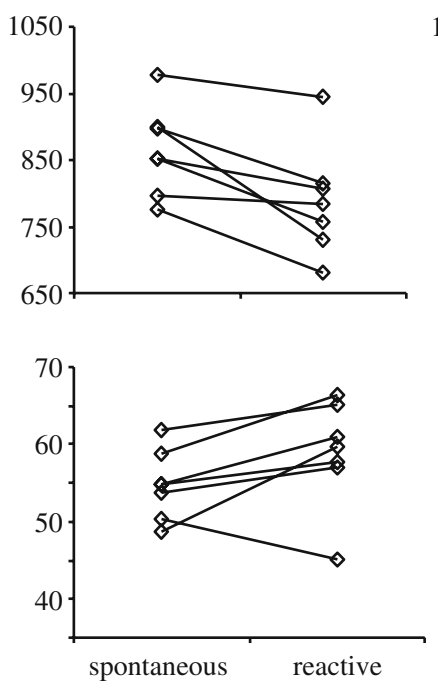

second k'tuc elements
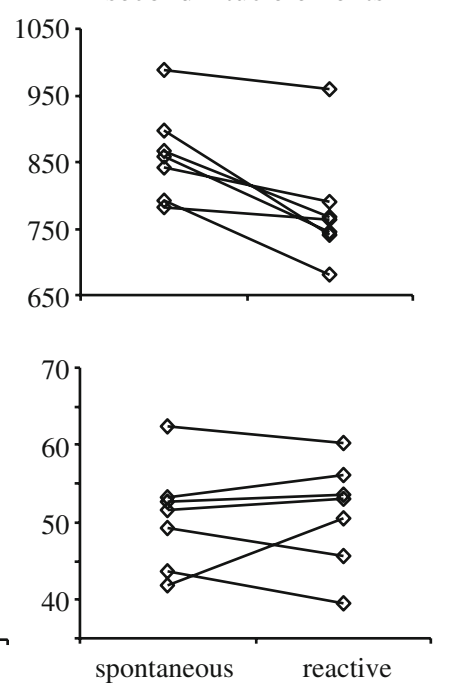
k'tuc elements, $t=-4.09, p=0.0003$; Mann-Whitney $U$ test: duration, whoots, $U=46, n_{1}=15, n_{2}=20, p=0.0003$; first k'tuc elements, $U=79, n_{1}=13, n_{2}=20, p=0.06$; second k'tuc elements, $\left.U=97, n_{1}=13, n_{2}=20, p=0.23\right)$. These context-specific changes were striking and clearly audible to the human ear. We could also hear them in natural territorial interactions between females but never outside an agonistic context (personal observations). An additional field observation was that females seemed to lower the amplitude of their song in synchrony with the spectrotemporal changes. However, we did not measure song amplitude quantitatively.

Morphometric correlates of acoustic properties

There was no significant relationship between morphometric measurements and the pitch of song elements when females were singing spontaneously - even though bootstrapped $95 \%$ confidence intervals of the effect size suggested a weak relationship between the MPF of first k'tuc elements and the mass of females (see S3 in the Electronic supplementary material). It is noticeable that, for both mass and tarsus length, the correlation coefficients were all negative. However, overall, larger females did not clearly sing with a lower pitched voice than smaller ones. This changed when females were singing reactively, i.e., when they vocally responded to the playback. In this context, larger females produced k'tuc elements with significantly lower MPF than smaller ones (Table 1).

\section{Context-specific use of the "coo" vocalization}

A specific type of vocal response, the coo (Fig. 1e), could occur during playback or in the $10 \mathrm{~min}$ following the playback. Six of the 22 subjects gave one or two coos in the 3-min period of playback, and one additional subject gave a coo in the $10 \mathrm{~min}$ following the playback. Thus, taken together, $32 \%$ of the subjects uttered coos when being challenged. In addition, we heard this type of vocalization in naturally occurring territorial disputes (personal observation and Goymann et al. 2004, 2008). In contrast, in the 5 min preceding the playbacks, none of the subjects ever produced this type of vocalization nor did we ever hear it from a spontaneously singing female.

\section{Discussion}

Female African black coucals changed features of their song when being challenged by a playback simulating a conspecific female: (1) they increased the proportion of whoots, a low-frequency element type; (2) they lowered the frequency and increased the duration of some of their song elements; and (3) they used an additional low-frequency type of vocalization, the coo, which they never used outside an agonistic context. Thus, all these changes put an emphasis on the low-frequency range of the species vocalizations. In addition, the pitch of k'tuc elements was negatively correlated to body size during reactive singing. Besides such context-dependent variation in the song, we found a few parameters to change over the course of the season: Spontaneously singing females produced song elements at lower pitch early in the breeding season. Likewise, females produced whoot elements of longer durations early in the breeding season when singing reactively.

Our results demonstrate that the song of female African black coucals contains context-specific variation in certain vocal parameters. Such vocal changes might indicate the motivation to escalate a contest and might be an important means to regulate the space between territorial females without engaging in costly physical fights.

As listed above, there was a whole set of different song features that females changed when being challenged, and

Table 1 Morphometric correlates of pitch

\begin{tabular}{|c|c|c|c|c|c|c|c|c|c|c|c|c|}
\hline & \multicolumn{6}{|c|}{ Spontaneous singing } & \multicolumn{6}{|c|}{ Reactive singing } \\
\hline & \multicolumn{2}{|l|}{ Mass } & \multicolumn{2}{|c|}{ Tarsus right } & \multicolumn{2}{|c|}{ Bill length } & \multicolumn{2}{|l|}{ Mass } & \multicolumn{2}{|c|}{ Tarsus right } & \multicolumn{2}{|c|}{ Bill length } \\
\hline & $r$ & $p$ & $r$ & $p$ & $r$ & $p$ & $r$ & $p$ & $r$ & $p$ & $r$ & $p$ \\
\hline Whoot & -0.16 & 0.44 & -0.32 & 0.12 & -0.09 & 0.68 & 0.12 & 0.73 & -0.55 & 0.10 & -0.09 & 0.80 \\
\hline 1st k'tuc & -0.29 & 0.16 & -0.29 & 0.15 & 0.20 & 0.33 & -0.21 & 0.56 & -0.79 & 0.01 & 0.22 & 0.54 \\
\hline 2nd k'tuc & -0.26 & 0.22 & -0.34 & 0.09 & 0.18 & 0.39 & -0.34 & 0.33 & -0.77 & 0.01 & 0.11 & 0.77 \\
\hline
\end{tabular}

Pearson correlation coefficients $(r)$ and respective $p$ values (significant $p$ values are given in italics, note that they remain significant if alpha is lowered according to sequential Bonferroni correction; $r$ also gives the effect sizes, and for lower and upper bootstrapped $95 \%$ confidence intervals of $r$ see S3 in the Electronic supplementary material). Pitch is given as MPF for each type of element (mean value per subject of mean value per song, for reactive singing: mean of the first songs produced after different test playbacks). Data are given for $n=25$ spontaneously singing females and $n=10$ reactively singing females 
one possibility to explain this diversity is that females might use different changes to express different levels of aggressive intent, a hypothesis that could be tested in future studies. Such a signaling system would allow for a very fine-tuned exchange of information and would be reminiscent of what has been suggested for song sparrows (Melospiza melodia), which use different types of patternspecific adjustment to an opponent's singing to express different levels of aggressiveness (Beecher et al. 1996, 2000; Burt et al. 2001, 2002, summarized in Beecher and Brenowitz 2005).

Female black coucals also altered spectro-temporal features over the course of the breeding season, mainly when singing spontaneously: Early in the season, they produced all types of song elements at lower pitch than later on. Reactively singing song sparrows use the signal type constituting a stronger threat more frequently early in the breeding season than later on (Beecher et al. 2000). This has been attributed to the relative instability of territory boundaries early in the season as opposed to established boundaries later on. Likewise, for African black coucals, it could be advantageous to use a more potent keep out signal (here, lower pitch) - even when just singing spontaneously-early in the breeding season, when territory boundaries are new and still unstable (cf. Krebs et al. 1981; Beecher et al. 2000).

Overall, our findings suggest that, in sex-role reversed species, signaling of females in a competitive context might be based on the same principles as in males of species with "typical" sex roles. Together with findings on female song under conditions of increased female-female competition in species with "typical" sex roles (Langmore 1998, 2000), they confirm the role of intra-sexual selection in the evolution of such signaling systems.

African black coucals lowered the frequency of some of their elements in the context of competition. Similar phenomena have already been described for "typical" sexrole species. Black-capped chickadees (Hill and Lein 1987) down-shifted their "fee bee" songs during vocal contests. In the song of Montezuma oropendolas (Psarocolius montezuma), the measured frequency parameter was lower during vocal interactions than during spontaneous singing (Price et al. 2006). A significant proportion of a population of scops owls (Otus scops) lowered a frequency component of their territorial call in response to stimuli mimicking a heavy individual versus a light individual (Hardouin et al. 2007). Such modifications seem to follow a common scheme across diverse taxa: Low-frequency sounds are used during aggressive encounters (in line with the motivation-structural rules proposed by Morton 1977). Such a context-specific use of low-frequency sounds might be related to a sizefrequency allometry. The size of the vocal apparatus is likely to be physically limited by body size and might in turn influence the frequency of vocalizations, e.g., by sizedependent resonance properties of the vocal tract (Fitch 1999). Hence, in lowering their voice, black coucals might go to their physical performance limits of sound production and thereby provide an honest signal of their body size. The use of such signals in aggressive contexts that are close to performance limits of sound production have recently been described in swamp sparrows (Melospiza georgiana), although they face another kind of performance limit: They increase both trill rate and frequency bandwidth in aggressive contexts, two acoustic parameters that are difficult to increase simultaneously (DuBois et al. 2009). The finding that the coucals show such context-specific variation only at the beginning of their vocal response toward a territorial challenge and then quickly returned to their default acoustic parameters suggest that they might face a condition-dependent performance limit when producing low-pitched and long song elements. Larger birds might be better able to produce such elements. However, whether or not such a size-frequency allometry exists has been a matter of debate. Results for relevant comparisons within species are contradictory: For some species, a correlation between frequency of song and body size could be demonstrated (e.g., Galeotti et al. 1997) but not for others (e.g., Bowman 1979; Shy 1983; Hardouin et al. 2007). Likewise, when both sexes use a similar vocalization, it is usually, but not always, lower in the larger sex (Ballintijn and ten Cate 1997). At an interspecific level, comparative studies revealed that larger bird species produce lower pitched vocalizations (e.g., Wallschlaeger 1980; Ryan and Brenowitz 1985), even when controlled for phylogeny (Tubaro and Mahler 1998). On the other hand, examining phylogenetically independent contrasts, Laiola and Rolando (2003) could not find such a relationship for the genus Corvus.

We found a negative correlation between tarsus length, which is indicative of body size, and the MPF of the k'tuc elements in African black coucals, but only when females were responding to a playback simulating an intruder. Thus, during a vocal contest, females might signal their competitive ability by producing their lowest possible k'tuc elements. However, the fact that whoots are even lower pitched than k'tucs argues against this interpretation, unless modes of production would differ for whoots and k'tcus and would be differently constraint. We did not find significant relationships between other morphometric measures (bill length and mass) and MPF either in reactive nor spontaneous singing. Mass might vary with the progression of egg laying (for which we do not have data), which might explain the lack of significant correlations. Interestingly, we did not also find a significant relationship between body measurements and frequency in spontaneously singing female black coucals, but the fact that most of the 
correlation coefficients had the same sign (they were negative) suggests that, even in spontaneously singing females, a weak relationship exists (by chance one would expect half of the coefficients to be positive and half of them to be negative). Thus, such relationships in spontaneously singing females might only be detectable with a larger sample size. Such relationships get stronger in challenged females. Possibly, they are more inclined to go to their physical performance limit when being challenged. Similar findings have been revealed by a study on American toads where the dominant call frequency more strongly correlates with body size for interacting than for non-interacting males (Bufo americanus, Howard and Young 1998). In reactively singing African black coucals, it is, however, counterintuitive that relationships between body measurements and pitch are strongest in elements that become less common (i.e., k'tucs), and it might be that other factors, e.g., differential habitat transmission or auditory perceiver sensitivity of high- versus low-frequency sounds in long- versus short-range interactions, play a role here as well. Further studies are needed to determine the nature of this relationship in more detail. Still, our findings might explain why some bird song studies did not find evidence for a size-frequency allometry if they were looking at spontaneous singing alone. We would like to encourage future researchers to examine acoustic properties both in territorially challenged birds and in spontaneously singing birds, when searching for such relationships.

Another study in a non-passerine species, the gray partridge (Perdix perdix) related sound frequency and duration to mating success and showed that successful males had lower pitched and longer vocal elements than unsuccessful males (Beani and Dessì-Fulgheri 1995). Also, low frequency and long duration of vocalizations could be induced by testosterone treatment (Fusani et al. 1994; Beani et al. 1995). Thus, acoustic variation reported for the gray partridge was similar to that found for African black coucals. The testosterone-induced acoustic changes in partridges occurred over a long time scale. However, in principle, steroid hormones can influence vocal parameters within a few minutes, as has been shown for midshipman fish (Porichthys notatus, Remage-Healey and Bass 2004). This raises the interesting question whether context-specific changes in the vocalizations of African black coucal might be related to hormonal changes during an agonistic context (Goymann et al. 2008).

In conclusion, we could demonstrate that female African black coucals change acoustic properties with the social context. Our interpretation of these findings is that they might do so to express their aggressive intent. Furthermore, when being challenged, they might vocalize at their performance limit and, thus, may honestly signal their competitive ability.
Acknowledgments We are grateful to the Tanzania Commission of Science and Technology (COSTECH), the Tanzania Wildlife Research Institute (TAWIRI), Dr Felister Urasa from the University of Dar es Salaam, Tanzania, and the management of the Kapunga Rice Irrigation Project for the permission to conduct this study. We thank Raimund Barth, Mackubi Joseph, Liz Mackley, Musa Makomba, Ingrid Schwabl, and Andrea Wittenzellner for help in the field. Sonja and Andreas Kümmerle and Liz and Neil Baker provided logistic support in Tanzania. We thank Henrik Brumm, Paula den Hartog, Erwin Ripmeester, Machteld Verzijden, and Hans Slabbekoorn for suggestions and discussions. Thanks to Carola Schmidt-Wellenburg for lending equipment, Rob Lachlan for providing and adjusting the sound analysis software "Luscinia," and Holger Schielzeth for statistical advice. Robert Gibson, two anonymous referees as well as Gabriel Beckers and Silke Kipper made helpful comments on the manuscript. This study was funded by a research grant from the Association for the Studies of Animal Behaviour (ASAB) to NG, by grants no. GE 1253/3-1 and GE 1253/3-2 from the Deutsche Forschungsgemeinschaft to NG, and grant no. GO 985/5-1 from the Deutsche Forschungsgemeinschaft to WG.

Open Access This article is distributed under the terms of the Creative Commons Attribution Noncommercial License which permits any noncommercial use, distribution, and reproduction in any medium, provided the original author(s) and source are credited.

\section{References}

Andersson M (1994) Sexual selection. Princeton University Press, Princeton

Andersson M (2005) Evolution of classical polyandry: three steps to female emancipation. Ethology 111:1-23

Ballintijn MR, ten Cate C (1997) Sex differences in the vocalizations and syrinx of the collared dove (Streptopelia decaocto). The Auk 114:22-39

Ballintijn MR, ten Cate C (1999) Variation in number of elements in the perch-coo vocalisation of the collard dove (Streptopelia decaocto) and what it may tell about the sender. Behaviour 136:847-864

Beani L, Dessì-Fulgheri F (1995) Mate choice in the grey partridge, Perdix perdix - role of physical and behavioral male traits. Anim Behav 49:347-356

Beani L, Panzica G, Briganti F, Persichella P, Dessi-Fulgheri F (1995) Testosterone-induced changes of call structure, midbrain and syrinx anatomy in partridges. Physiol Behav 58:1149-1157

Beecher MD, Brenowitz EA (2005) Functional aspects of song learning in birds. Trends Ecol Evol 20:143-149

Beecher MD, Stoddard PK, Campbell SE, Horning CL (1996) Repertoire matching between neighbouring song sparrows. Anim Behav 51:917-923

Beecher MD, Campbell SE, Burt JM, Hill CE, Nordby JC (2000) Song-type matching between neighbouring song sparrows. Anim Behav 59:21-27

Berglund A, Rosenqvist G (2003) Sex role reversal in pipefish. Adv Study Behav 32:131-167

Berglund A, Bisazza A, Pilastro A (1996) Armaments and ornaments: an evolutionary explanation of traits of dual utility. Biol J Linn Soc 58:385-399

Bortz J, Lienert GA, Boehnke K (1990) Verteilungsfreie methoden in der biostatistik. Springer, Berlin

Bowman RI (1979) Adaptive morphology of song dialects in Darwin's finches. J Ornithol 120:353-389 
Burt JM, Campbell SE, Beecher MD (2001) Song type matching as threat: a test using interactive playback. Anim Behav 62:1163-1170

Burt JM, Bard SC, Campbell SE, Beecher MD (2002) Alternative forms of song matching in song sparrows. Anim Behav 63:11431151

Brunton DH, Li XL (2006) The song structure and seasonal patterns of vocal behavior of male and female bellbirds (Anthornis melanura). J Ethol 24:17-25

Catchpole CK (1983) Variation in the song of the great reed warbler Acrocephalus arundinaceus in relation to mate attraction and territorial defense. Anim Behav 31:1217-1225

Catchpole CK, Slater PJB (2008) Bird song: biological themes and variations, 2nd edn. Cambridge University Press, Cambridge

Clutton-Brock T (2007) Sexual selection in males and females. Science 318:1882-1885

Cooney R, Cockburn A (1995) Territorial defense is the major function of female song in the superb fairy-wren, Malurus cyaneus. Anim Behav 49:1635-1647

DuBois AL, Nowicki S, Searcy WA (2009) Swamp sparrows modulate vocal performance in an aggressive context. Biol Lett 5:163-165

Eens M, Pinxten R (2000) Sex-role reversal in vertebrates: behavioural and endocrinological accounts. Behav Processes $51: 135-147$

Ekstrom JMM, Burke T, Randrianaina L, Birkhead TR (2007) Unusual sex roles in a highly promiscuous parrot: the Greater Vasa Parrot Caracopsis vasa. Ibis 149:313-320

Fitch WT (1999) Acoustic exaggeration of size in birds via tracheal elongation: comparative and theoretical analyses. J Zool 248:31-48

Fusani L, Beani L, Dessì-Fulgheri L (1994) Testosterone affects the acoustic structure of the male call in the grey partridge (Perdix perdix). Behaviour 128:301-310

Galeotti P, Saino N, Sacchi R, Moller AP (1997) Song correlates with social context, testosterone and body condition in male barn swallows. Anim Behav 53:687-700

Garamszegi LZ, Pavlova DZ, Eens M, Moller AP (2007) The evolution of song in female birds in Europe. Behav Ecol 18:86-96

Gil D, Gahr M (2002) The honesty of bird song: multiple constraints for multiple traits. Trends Ecol Evol 17:133-141

Goymann W, Wingfield JC (2004) Competing females and caring males. Sex steroids in African black coucals, Centropus grillii. Anim Behav 64:733-740

Goymann W, Wittenzellner A, Wingfield JC (2004) Competing females and caring males. Polyandry and sex-role reversal in African black coucals, Centropus grillii. Ethology 110:807823

Goymann W, Kempenaers B, Wingfield JC (2005) Breeding biology, sexually dimorphic development and nestling testosterone concentrations of the classically polyandrous African black coucal, Centropus grillii. J Ornithol 146:314-324

Goymann W, Wittenzellner A, Schwabl I, Makomba M (2008) Progesterone modulates aggression in sex-role reversed female African black coucals. Proc Biol Sci 275:1053-1060

Hardouin LA, Reby D, Bavoux C, Burneleau G, Bretagnolle V (2007) Communication of male quality in owl hoots. Am Nat 169:552562

Hill BG, Lein MR (1987) Function of frequency-shifted songs of black-capped chickadees. Condor 89:914-915

Howard RD, Young JR (1998) Individual variation in male vocal traits and female mating preferences in Bufo americanus. Anim Behav 55:1165-1179

Illes AE, Yunes-Jimenez L (2009) A female songbird out-sings male conspecifics during simulated territorial intrusions. Proc Biol Sci 276:981-986
Illes AE, Hall ML, Vehrencamp SL (2006) Vocal performance influences male receiver response in the banded wren. Proc Biol Sci 273:1907-1912

Järvi T, Radesater T, Jacobsson S (1980) The song of the willow warbler Phylloscopus trochilus with special reference to singing behaviour in agonistic situations. Ornis Scand 11:236242

Krebs JR, Ashcroft R, Vanorsdol K (1981) Song matching in the great tit Parus major L. Anim Behav 29:918-923

Kokko H, Jennions MD (2008) Parental investment, sexual selection and sex ratios. J Evol Biol 21:919-948

Laiola P, Rolando A (2003) The evolution of vocalisations in the genus Corvus: effects of phylogeny, morphology and habitat. Evol Ecol 17:111-123

Langmore NE (1998) Functions of duet and solo songs of female birds. Trends Ecol Evol 13:137-140

Langmore NE (2000) Why female birds sing. In: Espmark Y (ed) Adaptive significance of signalling and signal design in animal communication. Transactions of the Royal Norwegian Society of Sciences and Letters, Trondheim, pp 389-399

Ligon JD (1999) The evolution of avian breeding systems. Oxford University Press, Oxford

Maurer G, Smith C, Susser M, Magrath RD (2008) Solo and duet calling in the pheasant coucal: sex and individual call differences in a nesting cuckoo with reversed size dimorphism. Aust J Zool 56:143-149

Mennill DJ, Ratcliffe LM (2004) Overlapping and matching in the song contests of black-capped chickadees. Anim Behav $67: 441-450$

Morton ES (1977) On the occurrence and significance of motivational-structural rules in some bird and mammal sounds. Am Nat 111:855-869

Mundry R, Fischer J (1998) Use of statistical programs for nonparametric tests of small samples often leads to incorrect P values: examples from Animal Behaviour. Anim Behav $56: 256-259$

Nelson DA, Croner LJ (1991) Song categories and their functions in the field sparrow (Spizella pusilla). The Auk 108:42-52

Otter KA, Ratcliffe L, Njegovan M, Fotheringham J (2002) Importance of frequency and temporal song matching in blackcapped chickadees: evidence from interactive playback. Ethology 108:181-191

Price JJ, Earnshaw SM, Webster MS (2006) Montezuma oropendolas modify a component of song constrained by body size during vocal contests. Anim Behav 71:799-807

Price JJ, Yunes-Jimenez L, Osorio-Beristain M, Omland KE, Murphy TG (2008) Sex-role reversal in song? Females sing more frequently than males in the Streak-backed Oriole. Condor 110:387-392

Price JJ, Lanyon SM, Omland KE (2009) Losses of female song with changes from tropical to temperate breeding in the New World blackbirds. Proc Biol Sci 276:1971-1980

Rappole JH, Tipton AR (1991) New harness design for attachment of radio transmitters to small passerines. J Field Ornithol 62:335-337

Remage-Healey L, Bass AH (2004) Rapid, hierarchical modulation of vocal patterning by steroid hormones. J Neurosci 24:58925900

Riebel K (2003) The 'mute' sex revisited: vocal production and perception learning in female songbirds. Adv Study Behav 33:49-86

Riebel K, Hall ML, Langmore NE (2005) Female songbirds still struggling to be heard. Trends Ecol Evol 17:133-141

Ryan MJ, Brenowitz EA (1985) The role of body size, phylogeny, and ambient noise in the evolution of bird song. Am Nat $126: 87-100$ 
Schielzeth H, Forstmeier W (2009) Conclusions beyond support: over-confident estimates in mixed-models. Behav Ecol 20:416-420

Searcy WA, Nowicki S (2005) The evolution of animal communication: reliability and deception in signaling systems. Princeton University Press, Princeton

Shy E (1983) The relation of geographical variation in song to habitat characteristics and body size in North American tangers (Thraupinae:Piranga). Behav Ecol Sociobiol 12:71-76

Siegel S, Castellan NJ (1988) Nonparametric statistics for the behavioural sciences. McGraw-Hill, New York

Slater PJB, Mann NI (2004) Why do the females of many bird species sing in the tropics? J Avian Biol 35:289-294

Staicer CA (1996) Acoustic features of song categories of the Adelaide's warbler (Dendroica adelaidae). The Auk 113:771783
Stutchbury BJM, Morton ES (2001) Behavioral ecology of tropical birds. Academic, San Diego

ten Cate C, Slabbekoorn H, Ballintijn MR (2002) Birdsong and male-male competition: causes and consequences of vocal variability in the collared dove (Streptopelia decaocto). Adv Study Behav 31:31-75

Todt D, Naguib M (2000) Vocal interactions in birds: the use of song as a model in communication. Adv Study Behav 29:247-296

Trillo PA, Vehrencamp SL (2005) Song types and their structural features are associated with specific contexts in the banded wren. Anim Behav 70:921-935

Tubaro PL, Mahler B (1998) Acoustic frequencies and body mass in New World doves. Condor 100:54-61

Vernon CJ (1971) Notes on the biology of the black coucal. Ostrich 42:242-258

Wallschlaeger D (1980) Correlation of song frequency and body weight in passerine birds. Experientia 36:412 